\title{
Enhancement of Human Blood Storage Period by Irradiation of Low Level He-Ne Laser
}

\author{
Samira M. Sallam¹, Abdelsattar M. Sallam², El-Sayed M. El-Sayed², L. I. Abo Salem¹, \\ Mona M. Rizk ${ }^{1}$ \\ ${ }^{1}$ Department of Physics, Faculty of Science, Benha University, Benha, Egypt \\ ${ }^{2}$ Department of BioPhysics, Faculty of Science, Ain Shams University, Cairo, Egypt \\ Email: drsmsallam@yahoo.com
}

Received 3 July 2015; accepted 11 August 2015; published 14 August 2015

Copyright (C) 2015 by authors and Scientific Research Publishing Inc.

This work is licensed under the Creative Commons Attribution International License (CC BY).

http://creativecommons.org/licenses/by/4.0/

c) (i) Open Access

\begin{abstract}
The aim of the present work is to investigate the effect of the He-Ne laser irradiation on the whole human blood (HB) in order to enhance the conditions of conservation. The HB was irradiated by He-Ne laser; ( $\lambda=632 \mathrm{~nm}$, continuous wave, power $30 \mathrm{~mW}, 2 \mathrm{~mm}$ diameter beam spot), electrical properties and complete blood count CBC were measured at three doses $[0.0287,0.0563$ and 0.198 $\mathrm{J} / \mathrm{cm}^{3}$ ) to the relevant best exposure dose during storage periods $9,24,30,35 \& 50$ days. The irradiation process with the selected dose was performed by the exposure of the laser beam on the blood sample flow through narrow tube of cross section area, $0.0831 \mathrm{~cm}^{2}$. Blood dielectric parameters, (electric conductivity, dielectric constant, dielectric loss and dipole moment) and $\mathrm{CBC}$, (red blood cell, white blood cell, hematocrit, hemoglobin, mean corpuscular volume, mean corpuscular hemoglobin, and mean cell or corpuscular hemoglobin in concentration) were measured. The obtained results were compared with that of the control and showed that the best irradiation exposure dose suitable for increasing the time of blood storage with minimum changes in properties is $0.198 \mathrm{~J} / \mathrm{cm}^{3}$ and storage period of about 50 days. The present study revealed that irradiation by He-Ne laser could be considered a good means to improve the conservation conditions of human blood.
\end{abstract}

\section{Keywords}

He-Ne Laser, Whole Blood Storage, Electrical Properties, Dielectric Constant 


\section{Introduction}

Biostimulation effects of laser irradiation on living organisms were found for three decades [1]-[4]. The investigation of the interaction of laser radiation with biological tissues is of great interest because it permits not only obtaining information on their characteristics but also changing them [5].

The study of the low level laser irradiation effects on blood is very important in the process of revealing the mechanisms of the action of laser radiation on biological tissues, as the blood is permanently composed of a diversity of cells whose membranes contains lipids, sugars and proteins. Blood plasma probably contains the most diverse range of biological products among all tissues, some being intrinsic to other organs (amino acids, proteins, lipids, hormones, antibodies and adjusting factors), exogenous substances or component substances (clotting and defense enzymatic systems, such as complement, etc.). Some of the substances present in the blood may act as primary acceptors of radiation [6]-[8].

Several clinical treatments with low-power laser irradiation have been applied to various pathologic processes, such as wound healing and tissue repair, as well as remodeling [9]-[12] play a more or less important role in achieving the biological effects [13]-[16].

There are widespread applications of low intensity laser irradiation in various areas of the medical field [11] [12]. The new method that propose for the rejuvenation of preserved Blood (i.e. increasing the ratio of young to old RBCs, a process that could possibly be explained by laser radiation enhancing hemolysis of old or nonfunctional RBCs) using laser blood irradiation is suspected to be viable, efficient, low-cost, non-invasive and pose non-invasive and pose no blood contamination risk. If this is true, the prospect for performing transfusions using the irradiated blood will be good, in the treatment of some severe or hematological diseases (various types of leukemia). The efficiency of this method was demonstrated when it's recorded, after irradiation, a positive modification of some markers of the blood's functional integrity in relation to the non-irradiated samples. Some studies have been reported on the effect of low power laser irradiation on human blood parameters, especially for the parameter of RBC [17]-[20]. More research is needed to be done to understand the respond of this parameter with low level laser irradiation.

The most used laser of low level laser studies are He-Ne laser emitting light at a wavelength of $632.8 \mathrm{~nm}$ [21]-[26]. There is a fact that low powered He-Ne laser irradiation produced a protective effect on RBC membranes, reducing hypotonic hemolysis and stabilizing the cell membrane [27]. RBC, HGB and HCT were strongly influenced by He-Ne laser action due to the strong absorption of irradiation light by HGB, but without damaging the RBCs [28].

The blood as well as all biological tissues represents a special class of heterogeneous systems. It is a complex system where various mechanisms of polarization such as dipole, Maxwell-Wagner's, electrochemical, etc. can be realized [29]. Any changes in blood physiology should produce changes in the blood electrical properties [30]. Dielectric properties of biological tissues depend mainly on the cellular tissue structure. They are used as a powerful tool for studying molecular and cellular parameters [31]-[33].

They are considered a good measure of the functional state of the membrane and cytoplasm of the cells (e.g., counter ion relaxation associated with intrinsic membrane changes, dipole reaction in cell membrane, conductivity transport in the extra-cellar medium and through the membrane and tissue water relaxation). Information about tissue structure and composition, e.g. water content or presence of a tumor, might be obtained by measuring the dielectric properties of the tissues [34]. The present study used He-Ne laser irradiation as a physical method for rejuvenation during preservation period.

The aim of the present study is to find whether as a result of low level He-Ne laser action, the possibility to increase the viability of blood and get rejuvenation, in order to perform transfusion, as well as prolong its life preserved at $4^{\circ} \mathrm{C}$.

\section{Materials and Methods}

\subsection{Blood}

\subsubsection{Subjects}

Blood samples were obtained from 5 adult volunteers (female regular blood donors), after oral informed consent. According to local laws, neither medical ethic committee approval nor written consent is required. Blood samples from donors were referred for the standard blood analyses. In order to ensure the request of blinding method, 
only the coordinator of the study has access to all gathered data.

\subsubsection{Preparation of the Samples}

Blood samples: were prepared from the whole blood of healthy donors, preserved in Macopharma bags, and treated with CPD (sodium citrate as anticoagulant + P, D as preserver). CPD is used to store human blood for periods of about 21 days. To have more samples per volunteer, the original bags were separated into smaller bags prior to getting the blood each sample being able to collect about $10 \mathrm{ml}$ of blood.

Blood bag: A Blood bag of $450 \mathrm{ml} \pm 10 \%$ (Agarry) which contains CPDA-1 was used. Most blood collection bags (adult) contain $63 \mathrm{ml}$ CPDA anticoagulant Fresh human blood was obtained from ten healthydonor. Thirty small bag samples were papered to determine the normal dynamics of some dielectric, blood count parameters during the preservation period. They are divided into six groups stored, one control and five group's irradiated with He-Ne laser. The blood samples were storage before and after irradiation in transfused bags at $6^{\circ} \mathrm{C}-8^{\circ} \mathrm{C}$ for $(9,24,30,35 \& 50)$ days. c) Irradiation method Irradiation was carried out using a source of He-Ne laser (U.S.PAT. 311, 969), continues wave, $632.8 \mathrm{~nm}, 2 \mathrm{~mm}$ spot diameter, $30 \mathrm{~mW}$, for three doses $0.0287,0.0563$ and $0.198 \mathrm{~J} / \mathrm{cm}^{3}$ to relevant the best exposure dose during storage periods $9,24,30,35 \& 50$ days. The laser beam was in contact to the narrow rubber tube through which blood flow, as shown in Figure 1 [1].

\subsection{The Dielectric Measurements}

The dielectric measurements were carried out using LCR meter bridge (HIOKI 3531, Japan) in the frequency range $50 \mathrm{~Hz}$ to $100 \mathrm{KHz}$. A parallel plate conductivity cell was used with platinum electrodes, of area " $A$ " 0.48 $\mathrm{cm}^{2}$ and separating distance " $d$ " $1 \mathrm{~cm}$. The measured parameters were capacitance $c$ and conductance $G$ and consequently the dielectric constant $\dot{\varepsilon}$, the dielectric loss $\varepsilon^{\prime \prime}$ and the conductivity $\sigma$, and electrical dipole moment $D$ could be calculated from the following relations;

$$
\begin{gathered}
\dot{\varepsilon}=\frac{c}{\varepsilon_{\circ}} \frac{d}{A} \\
\sigma=G \frac{d}{A} \\
\varepsilon^{\prime \prime}=\varepsilon^{\prime} \tan \delta \\
D=\sqrt{\frac{2 k T \Delta \varepsilon}{N C}}
\end{gathered}
$$

where, $T$ is the absolute temperature, $N$ is Avogadro's number, $K$ is Boltzmann's constant and $C$ is the hemoglobin concentration.

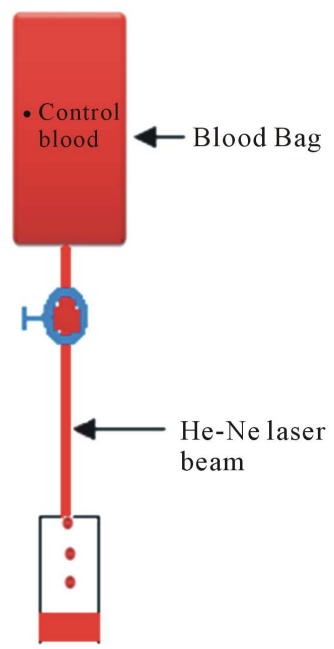

Figure 1. He-Ne Irradiation method. 
The plot of dielectric loss $\varepsilon^{\prime \prime}$ against the dielectric constant $\varepsilon^{\prime}$ is in the form of a semicircle whose center lies below the abscissa and intersects the axis at the points $\varepsilon_{\infty}^{\prime}$ and $\varepsilon_{s}^{\prime}$ (Figure 2). This is known as Cole-Cloe circle [35].

Since the center of the semicircle makes an angle $\alpha \pi / 2$ rad with the points $\left(\varepsilon_{s}^{\prime}\right)$ or $\left(\varepsilon_{\infty}^{\prime}\right)$. one can determine relaxation time $\tau_{0}$ using the relation:

$$
\frac{v}{u}=\left(\omega \tau_{0}\right)^{1-\alpha}
$$

where $\tau_{0}$ is the relaxation time and $\mu, v$ are the distances on the cole-cole diagram (Figure 2). Knowing $\tau_{o}$, the value of the molecular relaxation time $(\tau)$ is given by:

$$
\tau=\left[\frac{2 \varepsilon_{s}^{\prime}+\varepsilon_{\infty}^{\prime \prime}}{3 \varepsilon_{s}^{\prime}}\right]
$$

\section{Results and Discussion}

The human blood (HB) was exposed to continuous waves of $30 \mathrm{~mW}$ He-Ne laser, $632.8 \mathrm{~nm}$ and $2 \mathrm{~mm}$ spot diameter through during preservation periods $9,24,30,35$, and 50 days. The obtained data of the dielectric parameters and CBC before and after irradiation are summarized in Table 1 and Figure 3.

Figure 3(a) shows the variation in conductivity $(\sigma)$ of human blood with frequency after irradiation by three doses $\left(0.0287,0.0563\right.$ and $\left.0.198 \mathrm{~J} / \mathrm{cm}^{3}\right)$ of He-Ne laser in comparison with control values. It was found a decrease in the conductivity values for the three doses lower than that for control. The conductivity of dose 0.198 $\mathrm{J} / \mathrm{Cm}^{3}$ is the least decrease in conductivity in comparison with the other doses and hence it was selected and taken as the suitable and best dose to be used in this work.

Figure 3(b) Indicates RBCs count for all doses. Figure 3(c) shows the variation in conductivity of HB control sample (un-irradiated) with the frequency during the storage periods. It was found that the conductivity increases with the running storage days $9,24,30,35, \& 50$. This increase may be attributed due to complex components of $\mathrm{HB}$; plasma, $\mathrm{RBC}_{\text {s }}$, water content, etc..., and to some hemolysis of $\mathrm{RBC}_{\mathrm{s}}$, during preservation period.

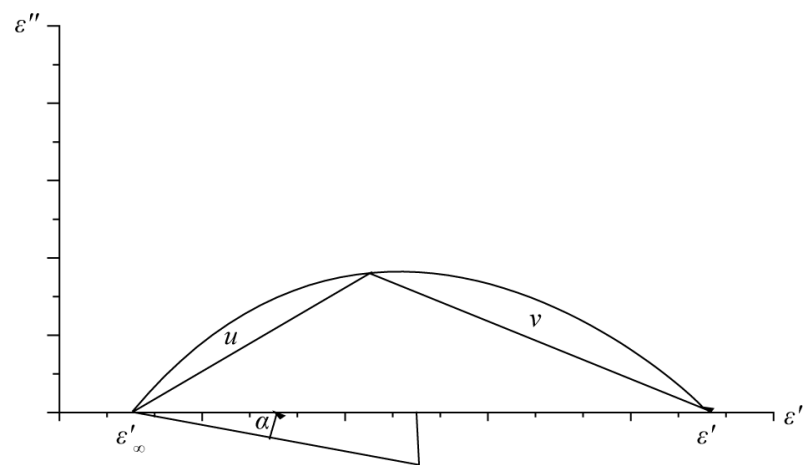

Figure 2. The cole-cole semicircle.

Table 1. The dielectric parameters for control and irradiated samples versus preservation days.

\begin{tabular}{ccccccccccccccc}
\hline $\begin{array}{c}\text { Storage } \\
\begin{array}{c}\text { period } \\
\text { (days) }\end{array}\end{array}$ & \multicolumn{2}{c}{$\Delta \varepsilon \times 10^{6}$} & \multicolumn{2}{c}{$\alpha$} & \multicolumn{2}{c}{$\tau \times 10^{-6}$} & \multicolumn{2}{c}{$\tau($ cole $) \times 10^{-6}$} & \multicolumn{2}{c}{$D \times 10^{-13}$} & \multicolumn{2}{c}{$f_{s}(\mathrm{~Hz})$} \\
\hline 9 & Control & Irrad. & Control & Irrad. & Control & Irrad. & Control & Irrad. & Control & Irrad. & Control & Irrad. \\
24 & 206 & 0.119 & 0.106 & 505.9 & 482 & 337.26 & 321.3 & 4.18 & 4.205 & 307.5 & 330.19 \\
30 & 212 & 196 & 0.113 & 0.101 & 518.28 & 537.6 & 345.59 & 358.4 & 4.26 & 4.102 & 307.08 & 296.04 \\
35 & 206 & 154 & 0.107 & 0.0947 & 536.76 & 546.1 & 357.33 & 364.1 & 4.20 & 3.636 & 296.5 & 291.4 \\
50 & 204 & 204 & 0.101 & 0.0885 & 665.9 & 563 & 443.9 & 375.33 & 4.18 & 4.184 & 238.97 & 282.6 \\
\hline
\end{tabular}




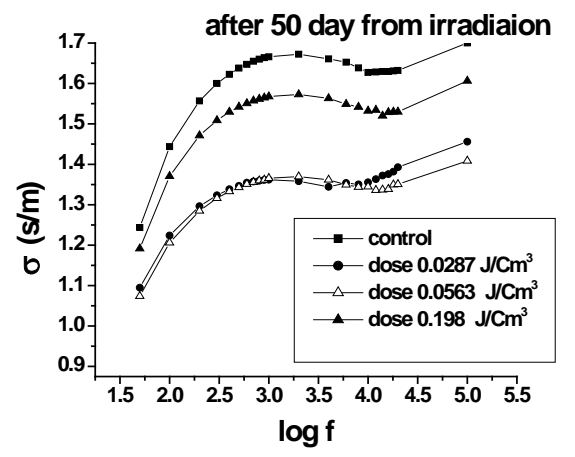

(a)

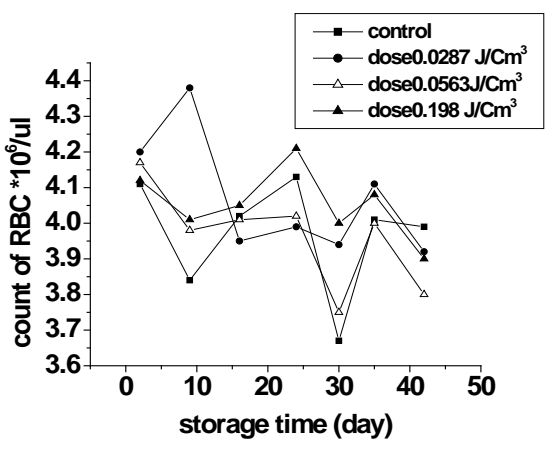

(b)

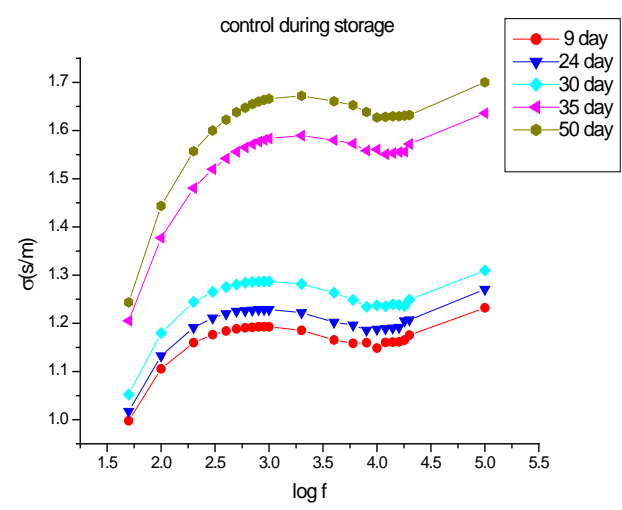

(c)

Figure 3. The obtained data of the dielectric parameters and RBCs count before and after irradiation, (a) conductivity of control and irradiated $\left(0.0287,0.0563\right.$ and $0.198 \mathrm{~J} / \mathrm{cm}^{3}$ doses) samples after 50 days; (b) $\mathrm{RBC}_{\mathrm{s}}$ counts of control and irradiated samples for different doses; (c) conductivity versus frequency of control samples during storage days (9, 24, 30, 35 \& 50).

The changes in HB conductivity due to laser irradiation dose of $0.198 \mathrm{~J} / \mathrm{cm}^{3}$ during storage periods $9,24,30$, 35 and 50 days is shown in Figure 4.

The conductivity of irradiated HB samples showed the same behavior of change with frequency as that of control samples but with lower values for all days of storage. This drop in conductivity may be attributed to the energy obtained by hemoglobin and oxygen activation and also due to laser irradiation which in turn lead to an increase in the cell membrane resistance which become more protective with increasing the storage period.

The relation between the dielectric loss $\left(\varepsilon^{\prime \prime}\right)$ and dielectric constant $(\dot{\varepsilon})$ of the human blood, in the frequency range from $50 \mathrm{~Hz}$ to $100 \mathrm{kHz}$ is shown in Figure 5, which represents Cole-Cole plots of the complex dielectric spectrum of blood before and after the effect of He-Ne laser irradiation during preserved days at $0.198 \mathrm{~J} / \mathrm{cm}^{3}$ dose.

It is clear from these figures that cole-cole plot for all samples were semicircles in which the control days are lower than that the irradiated.This is due to the increase in dielectric constant $\varepsilon$ and dielectric loss $\varepsilon$ " values after irradiation in comparison with control values. The increase in $\dot{\varepsilon}$ is perhaps due to higher polarization of ions in $\mathrm{RBC}_{\mathrm{s}}$ and water, while the increase of dielectric loss is due to the increase in dipole moment after irradiation as shown in Table 1. It was observed that values of $\Delta \varepsilon$ of RBCs after irradiation increased by an average value $1.03 \%$ compared with control value.

The center of the semicircles is not located at the $\mathrm{x}$-axis, but deviated below that axis where the radius of the circle making an angle $(\alpha \pi / 2)$ with the $\dot{\varepsilon}$ axis. Tan $\alpha \pi / 2$ is determined and hence the phase angle $(\alpha)$ is calculated. The experimental data of the variation in dielectric loss $\varepsilon^{\prime \prime}$ of HB with permittivity $\varepsilon$ for control sample (without irradiation) and irradiated samples during preservation days and other dielectric parameters calculated from the last figures are summarized in Table 1.

The blood was collected in bags with anticoagulant and preserving solution undergoes, through conservation days $(9,24,30,35$, and 50$)$ at $4^{\circ} \mathrm{C}$ to $6^{\circ} \mathrm{C}$, a natural process of aging or destruction because of stress. The $\mathrm{CBC}$ is 
favored process for getting the information about the functional state of the blood during storages days for control and irradiated samples as shown in Table 2.

The complete blood count CBC, represented the parameters, (red blood cell, RBC, white blood cell, WBC, hematocrit, HCT, mean corpuscular volume, MCV, mean corpuscular hemoglobin, MCH, and corpuscular hemoglobin in concentration, MCHC, as in Table 2.

The increase in $\Delta \varepsilon$ of RBC after irradiation is due to cell membrane activation of laser stimulus, which in turn cause diffusion of $\mathrm{K}^{+}, \mathrm{Na}^{+}$ions and absorption of laser energy by hemoglobin, these leading that the Na-K pump performed to recovery of cell membrane, while the increase in WBC in control samples perhaps due to defense of this cells for any abnormal variations in blood as the cell membrane of RBC is damage or its hemolysis while the decrease of WBC after irradiated during preservation refer to recovery of cell membrane and excess of protective of blood cell produced from the effects He-Ne laser at dose $0.198 \mathrm{~J} / \mathrm{cm}^{3}$.

The increase in hematocrit HCT is due the increase in $\mathrm{RBC}_{\mathrm{s}}$ [36]. Dan Georgel Siposan and Stefan Bobe, 2010 reported that, the complete recovery of the deposits is achieved by circulation within a few days after the transfusion. Though the hematocrit and hemoglobin clinically were increases immediately after transfusion. They suggested that the quantity of transfused blood for ensuring a normal oxyphoric function has to be approximately $10 \%$ larger than the estimated quantity ( $400-450 \mathrm{ml}$ of blood in order to increase hemoglobin by 1 $\mathrm{g} / 100 \mathrm{ml}$ of blood).

The values of MCV after irradiated slowly decreases than control values. Also MCH and MCHC values were slowly increases than control as shown in Table 2. These results due to that $\mathrm{K}^{+}$ions concentration exhibit a
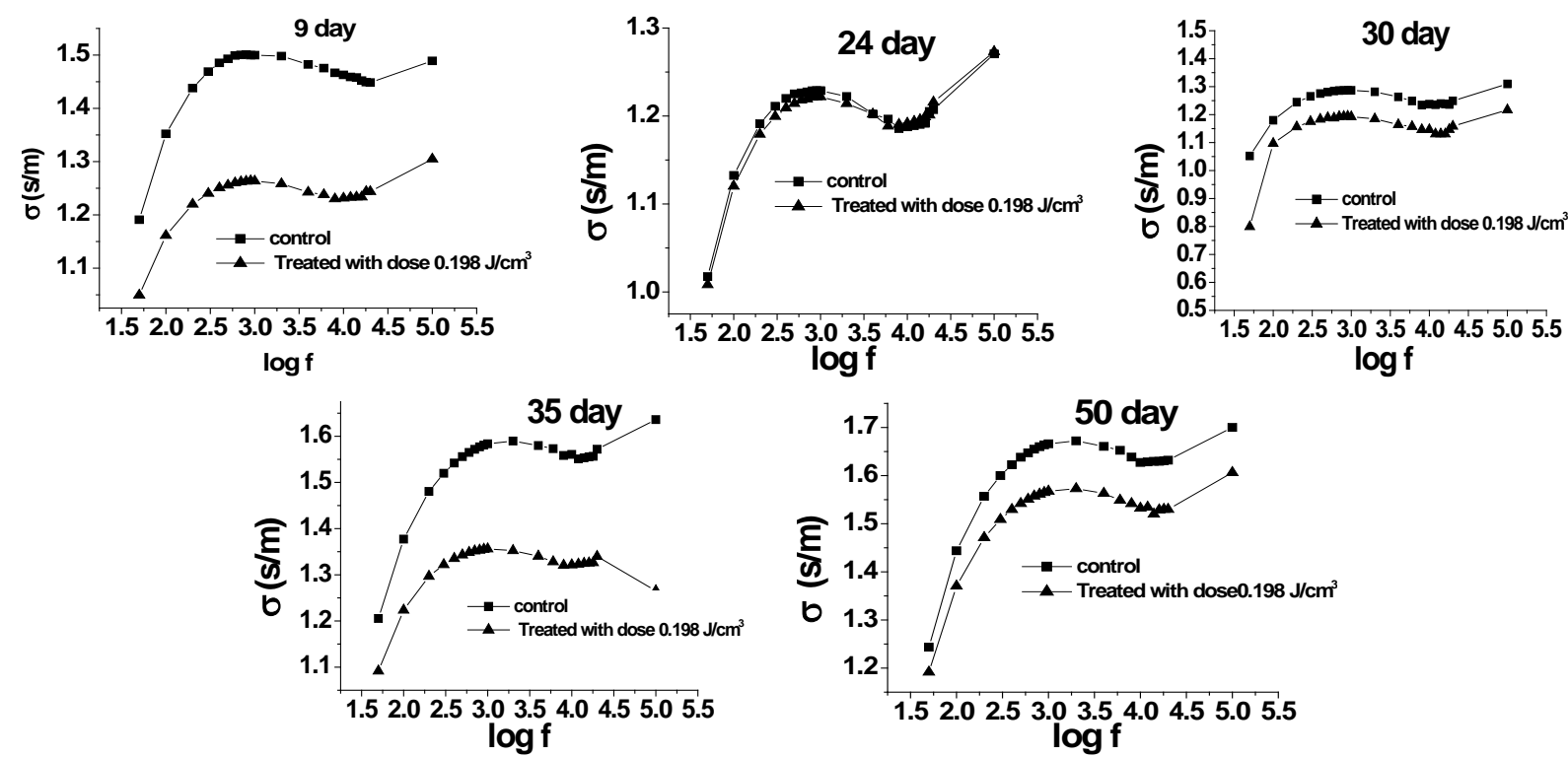

Figure 4. The variation in HB after laser irradiation by $0.198 \mathrm{~J} / \mathrm{cm}^{3}$ dose in comparison with control values during storage periods $9,24,30,35 \& 50$ days.

Table 2. CBC parameters of control and irradiated samples versus storage days.

\begin{tabular}{|c|c|c|c|c|c|c|c|c|c|c|c|c|}
\hline \multirow{2}{*}{ Days } & \multicolumn{2}{|c|}{$\mathrm{RBC}_{\mathrm{s}}$} & \multicolumn{2}{|c|}{ WBC } & \multicolumn{2}{|c|}{ HCT (\%) } & \multicolumn{2}{|c|}{$\operatorname{MCV}\left(\mu \mathrm{m}^{3}\right)$} & \multicolumn{2}{|c|}{ MCH (pg) } & \multicolumn{2}{|c|}{ MCHC (\%) } \\
\hline & Control & Irrad & Control & Irrad & Control & Irrad & Control & Irrad & Control & Irrad & Control & Irrad \\
\hline 9 & 3.84 & 4.01 & 4.5 & 4.6 & 34.2 & 34.4 & 86.7 & 85.9 & 30.2 & 29.9 & 34.8 & 34.9 \\
\hline 24 & 4.13 & 4.21 & 7.1 & 3.1 & 34.5 & 35.4 & 86.5 & 84.1 & 28.8 & 29.5 & 34.5 & 35 \\
\hline 30 & 3.67 & 4 & 8.8 & 5.5 & 31.4 & 34.6 & 85.5 & 86.6 & 30 & 30.3 & 35 & 35 \\
\hline 35 & 4.01 & 4.08 & 9.2 & 5.1 & 33.2 & 35.2 & 87.5 & 88.5 & 30.5 & 30.6 & 35.1 & 35.1 \\
\hline 50 & 4.1 & 4.21 & 10.1 & 4.7 & 37.1 & 38.1 & 90.5 & 90.4 & 32 & 32.1 & 35.3 & 35.4 \\
\hline
\end{tabular}



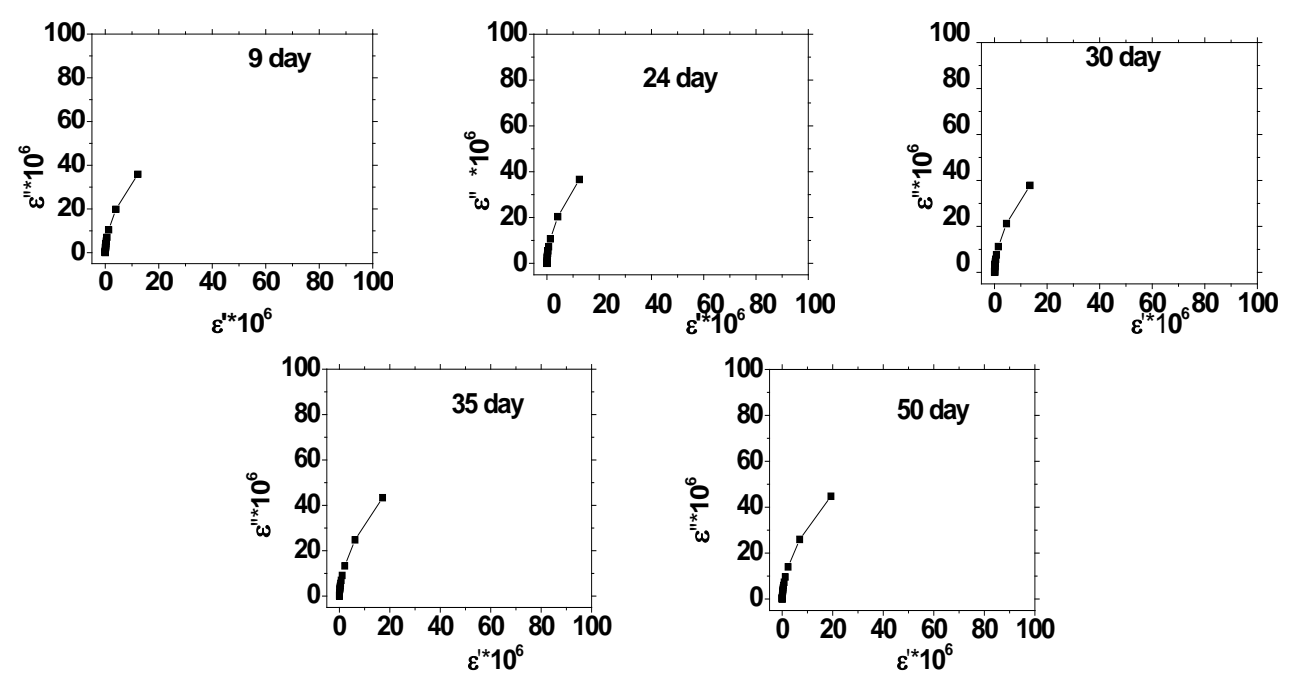

(a)
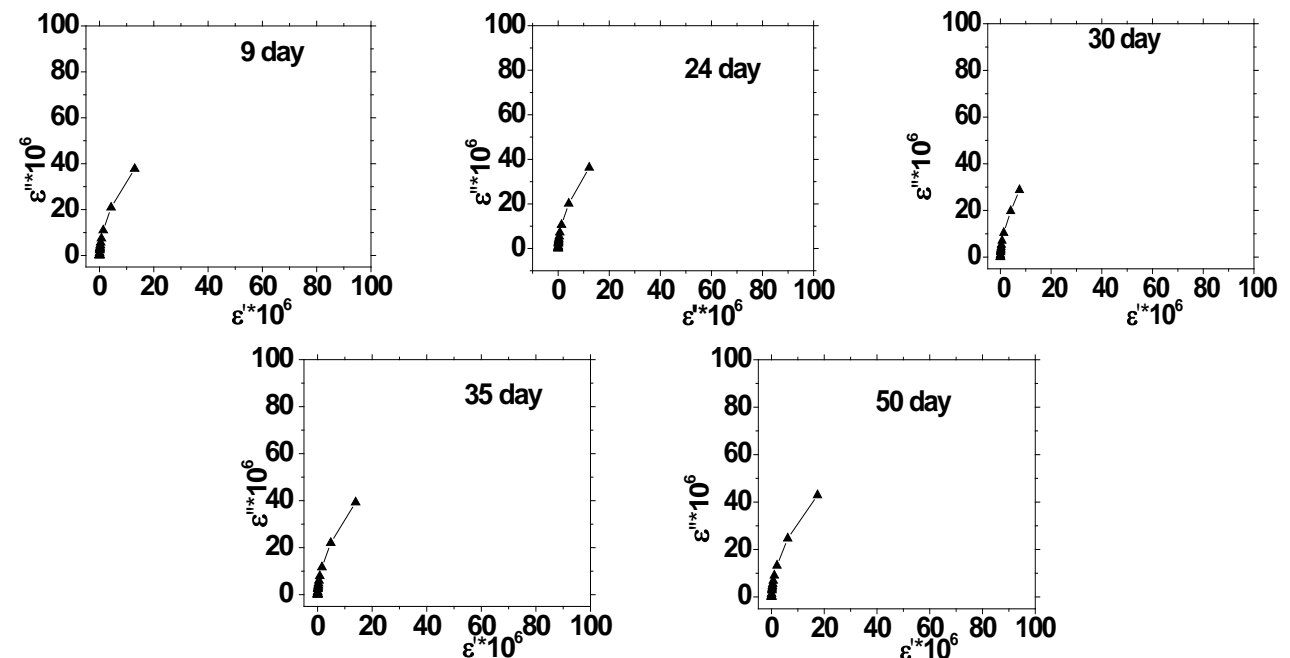

(b)

Figure 5. (a) The relation between the dielectric constant $(\dot{\varepsilon})$ and dielectric loss $\left(\varepsilon^{\prime \prime}\right)$ for control with preserved days; (b) the relation between dielectric constant $(\dot{\varepsilon})$ and dielectric loss $\left(\varepsilon^{\prime \prime}\right)$ after irradiation with $0.198 \mathrm{~J} / \mathrm{cm}^{3}$ of He-Ne laser at preserved days (9, 24, 30, 35 \& 50).

slight trend toward decrease and the $\mathrm{Na}^{+}$ions increase for certain dose $\left(0.2 \mathrm{~J} / \mathrm{cm}^{3}\right)$ agree with [36], this mean that the cell membrane return to normal condition and the shape of red blood cell remains constant, i.e. which laser radiation acts towards maintaining the shape of cells .The nearly stable of blood parameters after irradiation refer to the stable of red blood cell shape and not variable of skeleton. This accorded with Iglic et al. 1998, who [37] investigated that $\mathrm{RBC}_{\mathrm{s}}$ shape may be altered by varying different chemical and physical conditions which affect the properties of the membrane and volume of the cell, also other studies [38] [39] stated that $\mathrm{RBC}_{\mathrm{s}}$, maintain its shape by the filamentous network and stability of the lipid bilayer of the red cell membrane. The integrity of this protein has been shown to require red cell metabolism, specifically ATP production and cyclic nucleotide availability.

The total conductivity ( $\sigma$ ) of materials depends, in general, on its chemical composition, and hence the living tissues conductivity may also be affected by the changes in their chemical composition is very important because it may reflect the health status of the human.

From the obtained results it is evident that, the high value of the control conductivity $(\sigma)$ during storage days may be attributed to the high value of the membrane capacitance and conductance due to roughly explicable considering that the microvillus structure allows an higher ionic permeation with an increase of the ionic hydra- 
tion and also due to the inner solution (ionic hemoglobin) in $\mathrm{RBC}_{\mathrm{s}}$ [40]. As we notice from Figure 3; conductivity of whole human blood of control storage days increases with time due to the capacitance determines the amount of charge that can be stored across a membrane when a cell is exposed to an electric field [41]. Each living cell in the suspension assumes the behavior of a tiny electrical capacitor and the overall capacitance of the suspension rises as a function of the total biovolume (i.e. the volume fraction of the suspension which is enclosed by an intact membrane).

The results of CBC analysis support the dielectric parameters measurements, the conductivity of HB after irradiation decreases than its control value as in Figure 4, despite the increase of red blood cells count; this is due to increased polarization and also increases resistance of cell membrane rejuvenation (return after effect of He-Ne laser). This refer to the charged ions inside the cells are constrained to the cell volume. Trapped inside the membrane, the ions accumulate at the sides of the cell, and the cell becomes polarized. Clearly, only cells with undamaged membranes capable of electrical insulation contribute to the increase in capacitance [42]. This result agrees with [43], reported that the conductivity depends on the dynamical ionic transport through the membrane, so it is a measure of the permeability of the cell membrane. The permittivity is a measure of its polarizability in the electric field. It is related to the structure arrangement of the lipid bilayer and also to the conformation and localization of proteins in the membrane [44]. This polarization doesn't occur instantaneously, and the associated time constant is called the relaxation time, $\tau$ [45].

The dielectric loss curve can be evaluated by calculating its total area. It is proportional to the total concentration of dipoles in blood. The values of dipole moment for hemoglobin are registered in table [1] for control and after irradiation respectively. Its decrease in control than in irradiation during preserved days may be due to that the human blood (HB) after irradiation becomes higher stable in structure than control during preserving days. Consequently, the induced dipole moment goes through dispersion and decreases with increasing frequency.

\section{Conclusions}

In this study we had investigated the variation in HB dielectric parameters $\left(\sigma, \varepsilon^{\prime}, \varepsilon^{\prime \prime}, \tau \& D\right)$, due to laser irradiation as indication on the membrane structure and molecular motion. We mainly followed the conductivity variation, corroborated with polarization of $\varepsilon^{\prime}, \varepsilon^{\prime \prime}$ and dipole moment $D$. Also, this study investigates the variation in CBC parameters; RBC, WBC, HCT, MCV, MCH and MCHC, for irradiated and non-irradiated blood, as a function of preservation periods. In case of $\mathrm{CBC}$ parameters we mainly followed MCV, variation, corroborated with MCHC, MCH.

Generally, He-Ne laser radiation acts in the direction of maintaining the shape of cells, without leading to negative effect as spherocytosis and hemolysis, which normally occur in non-irradiated blood during the preservation period.

The obtained data suggested that most of the parameters under measurement were significantly modified by low level He-Ne laser effects with action of dose $0.198 \mathrm{~J} / \mathrm{cm}^{3}$, and consequently positively influenced on the preserved days.

The present study revealed that irradiation by He-Ne laser could be considered a good means to improve the conservation conditions of human blood.

\section{References}

[1] Mester, E., Mester, A.F. and Mester, A. (1985) The Biomedical Effects of Laser Application. Lasers in Surgery and Medicine, 5, 31-39. http://dx.doi.org/10.1002/lsm.1900050105

[2] Basford, J.R. (1995) Low Intensity Laser Therapy: Still Not an Established Clinical Tool. Lasers in Surgery and Medicine, 16, 331-342. http://dx.doi.org/10.1002/lsm.1900160404

[3] Lubart, R., Wollman, Y., Friedmann, H., Rochkind, S. and Laulicht, I. (1992) Effects of Visible and Infrared Lasers on Cell Cultures. Journal of Photochemistry and Photobiology B, 12, 305-310. http://dx.doi.org/10.1016/1011-1344(92)85032-P

[4] Sroka, R., Schaffer, M., Fuchs, C., Pongartz, T., Schrader-Reichard, U., Busch, M., Schaffer, P.M., Duhmke, E. and Baumgartner, R. (1999) Effect on Mitosis of Normal and Tumor Cells Induced by Light Treatment of Different Wavelength. Lasers in Surgery and Medicine, 25, 263-271. http://dx.doi.org/10.1002/(SICI)1096-9101(1999)25:3<263::AID-LSM11>3.0.CO;2-T

[5] Sturesson, C. and Andersson-Engels, S. (1996) Mathematical Modelling of Dynamic Cooling and Pre-Heating, Used to 
Increase the Depth of Selective Damage to Blood Vessels in Laser Treatment of Port Wine Stains. Physics in Medicine and Biology, 41, 413-428. http://dx.doi.org/10.1088/0031-9155/41/3/006

[6] Sevschenko, Iu.L., Matveev, S.A. and Cecetkin, A.V. (2000) Cardiosurgical Transfusiology. In: Chapter 6: The Photohemo-Therapy in the Therapy of Cardio-Surgical Patients, Clasic-Cosulting, Moscow. (Russian)

[7] Dillon, K.J. (1998) Healing Photons-The Science and Art of Blood Irradiation Therapy. Scientia Press, Washington DC.

[8] Brill, G.E. (2000) Molecular-Cellular Basis of the Therapeutic Action of Low-Intensity Laser Radiation. Didactic Textbook. Medical University, Saratov. (Russian)

[9] Halevy, S., Lubart, R., Reuveni, H. and Grossman, N. (1997) $780 \mathrm{~nm}$ low Power Laser Therapy for Wound Healing in Vivo and in Vitro Studies. Laser Ther, 9, 159-164. http://dx.doi.org/10.5978/islsm.9.159

[10] Surinchak, J.S., Alago, M.L. and Bellamy, R.F. (1983) Effects of Low Level Energy Lasers on the Healing of FullThickness Skin Defects. Lasers in Surgery and Medicine, 2, 267-274. http://dx.doi.org/10.1002/lsm.1900020310

[11] Lundeberg, T. and Malen, M. (1991) Low Power HeNe Laser Treatment of Venous Leg Ulcers. Annals of Plastic Surgery, 27, 537-539. http://dx.doi.org/10.1097/00000637-199112000-00004

[12] Kipshidze, N., Sahota, H., Wolinsky, H., Komorowsky, R.A., Boerboom, L.E., Keane, S.D., Keelan, M.H. and Baker, J.E. (1994) Photoremodeling of Atherosclerotic Wall Inhibits Myointimal Hyperplasia Following Balloon Angioplasty. Circulation, 90, 327-332.

[13] Mordon, S. and Michaud, T. (2009) Theory of Laser and Lamps. Annales de Dermatologie et de Vénéréologie, 136, S306-S310. http://dx.doi.org/10.1016/S0151-9638(09)72538-4

[14] Tuner, J. and Hode, L. (2002) Laser Therapy_Clinical Practice and Scientific Background. Prima Books, Grangesberg.

[15] Karu, T. (2007) The Science of Low-Power Laser Therapy. Prima Books, Grangesberg.

[16] Yokoyama, K. and Sugiyama, K. (2003) Influence of Linearly Polarized Near-Infrared Irradiation on Deformability of Human Stored Erythrocytes. Journal of Clinical Laser Medicine \& Surgery, 21, 19-22. http://dx.doi.org/10.1089/10445470360516699

[17] Zalesskaya, G.A. and Sambor, E.G. (2005) Interaction of Low-Intensity Laser Radiation with Blood and Its Components. Journal of Applied Spectroscopy, 72, 242-248. http://dx.doi.org/10.1007/s10812-005-0062-0

[18] Zalesskaya, G.A., Sambor, E.G. and Kuchinskii, A.V. (2006) Effect of Intravenous Laser Irradiation on the Molecular Structure of Blood and Blood Components. Journal of Applied Spectroscopy, 73, 115-122. http://dx.doi.org/10.1007/s10812-006-0045-9

[19] Mi, X.Q., Chen, J.Y., Cen, Y., Liang, Z.J. and Zhou, L.W. (2004) A Comparative Study of 632.8 and 532 nm Laser Irradiation on Some Rheological Factors in Human Blood in Vitro. Journal of Photochemistry and Photobiology B: Biology, 74, 7-12. http://dx.doi.org/10.1016/j.jphotobiol.2004.01.003

[20] Siposan, D.G. and Lukacs, A. (2000) Effect of Low-Level Laser Radiation on Some Rheological Factors in Human Blood: An in Vitro Study. Journal of Clinical Laser Medicine \& Surgery, 18, 185-195. http://dx.doi.org/10.1089/10445470050144038

[21] Relevy, H., Koshkaryev, A., Manny, N., Yedgar, S. and Barshtein, G. (2008) Blood Banking-Induced Alteration of Red Blood Cell Flow Properties. Transfusion, 48, 136-146.

[22] Sikurova, L., Balis, P. and Zvarik, M. (2011) Penetration of Laser Light through Red Blood Cell Ghosts. Journal of Photochemistry and Photobiology B: Biology, 103, 230-233. http://dx.doi.org/10.1016/j.jphotobiol.2011.03.015

[23] Mi, X.Q., Chen, J.Y. and Zhou, L.W. (2006) Effect of Low Power Laser Irradiation on Disconnecting the Membrane-Attached Hemoglobin from Erythrocyte Membrane. Journal of Photochemistry and Photobiology B: Biology, 83, 146-150. http://dx.doi.org/10.1016/j.jphotobiol.2005.12.018

[24] Cui, Y., Guo, Z., Zhao, Y., Zheng, Y., Qiao, Y., Cai, J., et al. (2007) Reactive Effect of Low Intensity He-Ne Laser upon Damaged Ultrastructure of Human Erythrocyte Membrane in Fenton System by Atomic Force Microscopy. Acta Biochimica et Biophysica Sinica, 39, 484-489. http://dx.doi.org/10.1111/j.1745-7270.2007.00309.x

[25] Gulsoy, M., Ozer, G.H., Bozkulak, O., Tabakoglu, H.O., Aktas, E., Deniz, G., et al. (2006) The Biological Effects of 632.8-nm Low Energy He-Ne Laser on Peripheral Blood Mononuclear Cells in Vitro. Journal of Photochemistry and Photobiology B: Biology, 82, 199-202. http://dx.doi.org/10.1016/j.jphotobiol.2005.11.004

[26] Brill, A.G., Shenkman, B., Brill, G.E., Tamarin, I., Dardik, R., Kirichuk, V.F., et al. (2000) Blood Irradiation by He-Ne Laser Induces a Decrease in Platelet Responses to Physiological Agonists and an Increase in Platelet Cyclic GMP. Platelets, 11, 87-93. http://dx.doi.org/10.1080/09537100075698

[27] Iijima, K., Shimoyama, N., Shimoyama, M. and Mizuguchi, T. (1991) Red and Green Low-Powered He-Ne Lasers 
Protect Human Erythrocytes from Hypotonic Hemolysis. Journal of Clinical Laser Medicine \& Surgery, 9, 385-389.

[28] Mostafa, Y.M., Amin, S.N., Abdalwahab, S. and Elsherbini, A.A.M. (2013) Effects of Non-Coherent and Coherent Light on Complete Blood Picture and Osmotic Fragility of Human Blood. Journal of Blood Disorders \& Transfusion, 4, 1000134.

[29] Chelidze, T. (2002) Dielectric Spectroscopy of Blood. Journal of Non-Crystalline Solids, 305, 285-294.

[30] Abdalla, A.S, Al-Ameer, S.S. and Al-Magaishi, S.H. (2010) Electrical Properties Relaxation through Human Blood. Biomicrofluidics, 4, 034101.

[31] Peyman, A., Holden, S. and Gabriel, C. (2010) Dielectric Properties of Tissues at Microwave Frequencies. C/O Health Protection Agency. Chilton, Did cot, Oxford Shire OX11 ORQ. www.mthr.org.uk

[32] Kuang, W. and Nelson, S.O. (1998) Low-Frequency Dielectric Properties of Biological Tissues, a Review with Some New Insights. American Society of Agricultural Engineers, 41, 173-184. http://dx.doi.org/10.13031/2013.17142

[33] Makio, W., Toshinobu, S. and Akihiko, I. (1991) Dielectric Behavior of the Frog Lens in the $100 \mathrm{~Hz}$ to $500 \mathrm{MHz}$ Range Simulation with an Allocated Ellipsoidal-Shells Model. Biophysical Journal, 59, 139-149.

[34] Talaat, M.S.E., Sallam, S.M., Negm, S.E., Metawe, F.M. and Khatab, H.F. (2014) Effect of Nd-YAG Laser on Dielectric Properties of Rabbit Eye. International Journal of Biological Sciences and Applications, 1, 162-169.

[35] Cole, K.S. and Cole, R.H. (1941) Dispersion and Absorption in Dielectrics I. Alternating Current Characteristics. The Journal of Chemical Physics, 9, 341-351. http://dx.doi.org/10.1063/1.1750906

[36] Siposan, D.G. and Bobe, S. (2010) Effects of HeNe Laser on Stored Blood. Laser Therapy, 19, 245-255. http://dx.doi.org/10.5978/islsm.19.245

[37] Iglic, A., Kralj-Iglic, V. and Hagerstrand, H. (1998) Amphiphile Induced Echinocyte-Spheroechinocyte Transformation of Red Blood Cell Shape. European Biophysics Journal, 27, 335-339. http://dx.doi.org/10.1007/s002490050140

[38] Suwalsky, M., Manrique, M., Villena, F. and Sotomayor, C.P. (2009) Structural Effects in Vitro of the Anti-Inflammatory Drug Diclofenac on Human Erythrocytes and Molecular Models of Cell Membranes. Biophysical Chemistry, 14, 34-40. http://dx.doi.org/10.1016/j.bpc.2008.12.010

[39] Park, Y., Best, C.A. Auth, T., Gov, N.S., Safran, S.A., Popescu, G., et al. (2010) Metabolic Remodeling of the Human Red Blood Cell Membrane. Proceedings of the National Academy of Sciences of the United States of America, 107, 1289-1294.

[40] Bordi, F., Cametti, C. and Di Biasio, A. (1990) Determination of Cell Membrane Passive Electrical Properties Using Frequency Domain Dielectric Spectroscopy Technique. A New Approach. Biochimica et Biophysica Acta, 1028, 201204.

[41] Selim, N.S., Desouky, O.S., Elbakrawy, E.M. and Rezk, R.A. (2010) Electrical Behavior of Stored Erythrocytes after Exposure to Gamma Radiation and the Role of A-Lipoic Acid as Radio Protector. Applied Radiation and Isotopes, 68, 1018-1024. http://dx.doi.org/10.1016/j.apradiso.2010.01.020

[42] Desouky, O.S. (2009) Rheological and Electrical Behavior of Erythrocytes in Patients with Diabetes Mellitus. Romanian Journal of Biophysics, 19, 239-250.

[43] Pethig, R. and Talary, M.S. (2007) Dielectrophoretic Detection of Membrane Morphology Changes in Jurkat T-Cells Undergoing Etoposide-Induced Apoptosis. IET Nanobiotechnology, 1, 2-9. http://dx.doi.org/10.1049/iet-nbt:20060018

[44] Bonincontro, A., Cametti, C., Rosi, A. and Sportelli, L. (1989) Electrical Parameters of Erythrocyte Membranes Deduced from Radiowave Conductivity Measurements. Journal of Membrane Science, 41, 345-354. http://dx.doi.org/10.1016/S0376-7388(00)82413-8

[45] Martinsen, O.G., Grimnes, S. and Schwan, H.P. (2002) Interface Phenomena and Dielectric Properties of Biological tissue. In: Somasundaran, P., Ed., Encyclopedia of Surface and Colloid Science Anonymous, Marcel Dekker, Inc., 2643-2652. 